\title{
Information society and the Digital Divide Problem in Developing Countries
}

\author{
Chrisanthi AVGEROU and Shirin MADON \\ London School of Economics, \\ c.avgerou@lse.ac.uk,s.madon@lse.ac.uk
}

\begin{abstract}
"... the root of counter-development obstacles to ICT, might be the extent to which the information society conveys aspirations, and privileges technologies, information and knowledge that are irrelevant to the way the majority of people in many communities in developing countries live their lives."
\end{abstract}

Key words: Digital divide, developing countries, social exclusion, marginalisation.

\section{INTRODUCTION}

Soon after its emergence in the USA and in Europe in the early 1990s, the information society discourse became linked with the discourse of development for the poorer countries of the world. In political rhetoric, policy documents, and international aid agency analyses the diffusion of information technology, the construction of modern telecommunications infrastructure, and the concomitant increase of communication and access to information resources were designated as sine qua non prerequisites for development. With few exceptions, developing countries, often assisted by international institutions, drafted strategies for their race towards becoming information societies and launched suitable initiatives. Nevertheless, and for many not entirely unexpectedly, by the end of the 1990s, the 'information societies' of the developing countries were a cause of apprehension within the international development fora. With rapidly increasing trends of globalisation spearheaded by the political and economic institutions of the 
advanced industrialised nations, the grossly uneven spread of ICTs around the world came to be seen as a digital divide at a global scale.

In this chapter, we examine the developmental significance of the information society vision and its accompanying threat, the digital divide. In the first section we review briefly the arguments that fuel plans and actions under the information society banner. We point out that the discourse on information society is based on the notion of development as 'catching up' with the advanced industrialised world, which involves aiming at the achievement of economic indicators of advanced industrialised countries by following their footsteps of technology and socio-organizational innovation. Catching up pressures and efforts are accompanied by the threat of marginalisation in the global free market economy. Another significant aspect of the information society discourse is the way it privileges knowledge, and information, seen as a-contextual resources with universal developmental value.

In the second section we examine current understanding of the digital divide problem and its link to the chronic socio-economic problems in many developing countries. We argue that the root of counter-development obstacles to ICT, that find their expression in terms of the digital divide problem, might be the extent to which the information society conveys aspirations, and privileges technologies, information and knowledge that are irrelevant to the way the majority of people in many communities in developing countries live their lives.

In the third section we suggest alternative ways of analysis to overcome the narrow techno-economic vision of information society and its accompanying concept of the digital divide. We propose to build on research approaches that avoid the universalistic discourse of ICT and development and are capable of shedding light on the particular, historically formed, circumstances within which ICTs and information resources acquire meaning. Specifically, we suggest three streams of theoretical work as promising approaches to that end: the conceptual perspective that challenges the a-contextual cognitive view of the information society, the analysis on hybridisation of culture in the context of globalisation highlighting the important role of intermediaries, and the work on social exclusion.

\section{THE INFORMATION SOCIETY DISCOURSE IN DEVELOPING COUNTRIES}

IT and telecommunications have always been perceived as opening unprecedented opportunities for developing countries. Early computers were seen as tools to assist their public bureaucracies to overcome endemic gross inefficiencies. It was suggested that microcomputers and educational 
software could stretch the limited capabilities of poorly trained teachers to introduce their pupils to the vital fields of science, technology, and train them with skills for modern business. Similarly, expert systems were considered capable of empowering their limited medical and nursing human resources. Such potential appeared to increase vastly with advances in telecommunications in the 1980s and 1990s. It is not difficult to perceive the possibilities of eGovernment, of enhancing education in even the most advanced topics and in the most remote communities, of practicing telemedicine, of accessing worldwide markets from any place of agricultural production, of gaining lucrative contracts on the basis of lower labour costs in a range of service industries.

Against this background of interest in ICT for development, the discourse on information society that emerged in industrialised countries in the 1990 s was quickly transferred into political circles, the international development agencies, the academic literature, and the popular debate arenas of most developing countries. Many high profile initiatives have been undertaken, typically aiming to create awareness on the benefits of ICT, raise investment, and promote policy measures for the deployment of telecommunications infrastructures and the diffusion of ICT applications in all societal sectors. Notable examples of such projects include the Digital Opportunity Task Force of the eight major industrial nations, G-8 (Dot force initiative, http://www.dotforce.org), the World Summit for the Information Society of the United Nations and the International Telecommunications Union (WSIS initiative, http://www.itu.int/wsis) and the World IT Forum of the International Federation of Information Processing (WITFOR programme, http://www.witfor.lt).

This wave of interest on ICT for development has two salient features: emphasis on information and knowledge, and the assumption of a global free market socio-economic context. Knowledge, learning and 'social capabilities' to innovate are highlighted as the most significant factor for development. For example, Mansell \& Wehn [1998] argue for the significance of knowledge-based economic growth and development, for which crucial determinants are infrastructure, experience of production and consumption, and skills. Along similar lines, the 1999 World Bank World Development Report entitled 'Knowledge for Development' [World Bank, 1999] saw IT as a powerful tool to fight poverty and underdevelopment. The report argued that the developmental significance of ICTs lies in its capacity to provide access to information sources and communication media necessary for building such social capabilities, in other words as tools for learning and innovation.

The learning that is suggested in the literature and policy manifestos of international agencies as crucial in supporting ICTs refers to acquiring capabilities to produce and use ICTs and to work out organisational changes 
that are conducive to continuous technology innovation. The battle of developing countries for their inclusion in the global information society involves the acceptance of a uni-directional flow of information and knowledge from the advanced industrialised world. There is recognition that tacit knowledge is significant in complementing formal and codified knowledge in the learning process, but even with regard to tacit knowledge it is often suggested that developing countries need to rely on the tacit knowledge existing in industrialised countries rather than their own: 'An optimistic scenario for developing countries in the face of the diffusion of ICTs envisages a massive transfer of tacit knowledge into information systems giving these countries access to new process technologies and products developed in the industrialised countries both rapidly and at low cost. In theory this would lead to an acceleration of the catching up process and a reduction in global inequalities' [Mansell \& Wehn, 1998].

Such a developmental role of ICT is understood to require specific socio-economic and organisational interventions, namely liberalisation, particularly of the telecommunications sector, and the reform of both business and government organisations towards a management-driven governance regime. This logic is presented clearly in influential publications by various development agencies such as the 2002 World Development Report, Building Institutions for Markets, of the World Bank [2002] and UNDP's 2001 Human Development Report, Making New Technologies Work for Human Development [2001]; and the two publications by the Center for International Development at Harvard University, The Global Information Technology Report: Readiness for the Networked World [Kirkman et al., 2002a,b], and The Global Competitiveness Report 20012002 [Porter et al., 2002].

All these publications propose ICT as an instrument for economic and social gains within a market regime, and they elaborate on the conditions under which ICT plays this kind of developmental role. The central issue in the discourse in these texts concerns the socio-economic conditions that are favourable for the mutual re-enforcement of ICT innovation and an effective market [Avgerou, 2003].

In this discourse ICT is seen to contribute to improvements of life conditions in developing countries through enabling market mechanisms. Interventions to develop community ICT services in poor regions bear implicit promises for economic benefits through participation in the global market. For example, there is a tendency to see ICT centres in poor communities as sustainable businesses in their own right [Best \& Maclay, 2002]. Moreover, the introduction of business management practices is seen as a necessary reform across the range of organizations and in particular for the rationalization of citizens/government interaction. Policy advice on eGovernment, for example, the DfID policy brief 'Making EGovernment 
work for poor people' and the G8 Action Plan 2002 'EGovernment for Development' emphasise the importance of introducing modern management practices and computerisation within government to enhance the delivery of public services.

But despite acknowledging the importance of socio-economic and institutional change to support ICT for development, the information society in developing countries is perceived mainly in technical terms as the construction of telecommunications infrastructures. The whole ICT for development literature gives scant attention to the demand side in terms of questioning the very purpose for which communities need knowledge, and what knowledge is appropriate for particular groups. For example, at a recent IFIP WG9.4 conference on ICTs and Development held in Bangalore [Krishna \& Madon, 2002], the majority of papers submitted were descriptions of pilot projects that aimed to establish the necessary infrastructure to facilitate communication and the processing and transmission of information by electronic means. Very few papers addressed the more fundamental question of how communication, information and knowledge can be effectively used as critical elements for poverty reduction and overall development.

\section{THE DIGITAL DIVIDE}

The Digital Divide has become something of a buzzword in policy circles, the popular press and academia. Norris [2001] categorises this divide into its three constituent elements: the global divide between advanced industrialised countries and developing countries, the social divide between information rich and information poor within advanced industrialised countries, and the democratic divide between those within the online community who do and do not use digital resources to engage, mobilise and participate in public life. Within each category, Norris and other writers [Wresch, 1996; Castells, 2001] discuss the divide primarily in terms of access to ICTs, rather than in terms of the information and knowledge which is of value in the context of the information society and in terms of the social capabilities for such learning as we discussed in the previous section. In economic terms, there are vast differences among developing countries' ability to produce or to effectively use ICTs and participate in the global economy. Indeed, the literature contains exemplary cases of countries with impressive progress in ICT innovation according to the information society characteristics outlined above - mainly some of the small economies of South East Asia, such as South Korea [Lee et al., 2003] - and a plethora of examples of promising initiatives and opening up of opportunities. Nevertheless, the overall picture is one of concern about the growing digital 
divide [Norris, 2001; Castells, 2001]. This is reflected in the literature from the World Bank, the OECD and individual agencies - 'The Digital Divide is one of the greatest impediments to development .... and it is growing exponentially' [Wolfensohn, 2000]. Leaders in Internet penetration are Scandinavia and North America followed by Western Europe with about one in five online. Central and Eastern Europe, Asia, the Middle East and South America fall below the world average with less than one in ten online, with minimal diffusion in Sub-Saharan Africa [Kirkman et al., 2002b].

Inequality in the deployment of the Internet is similar to inequalities of earlier forms of communication technologies like telephones and television. Taking figures from several different sources, Norris [2001] presents evidence to suggest that the global pattern of inequality in Internet use mirrors the broader pattern of access to earlier ICTs. The disparity of Internet access between developed and developing countries is therefore not particular to the nature of Internet technology, but due to deep-rooted and endemic contextual factors within those societies.

These results are not particularly surprising - it would be naïve to expect a lesser contrast in Internet diffusion given the substantial disparities in every other dimension of life including access to earlier forms of ICTs like telephones and television. Several influential and comprehensive studies of the global digital divide point to a significant positive relationship between levels of economic development and the global digital divide. For example, a study by Hargittai [1999] and another by Rodriguez and Wilson in a World Bank sponsored study [2000] found that the economic wealth of a country measured by per capita GNP was the most important predictor of Internet access. Yet, the discourse on the digital divide is keen to present the reverse causal association between ICT and economic conditions. Economic analyses portray ICT as a significant factor of growth in the context of modern competitive economies; consequently the lack of ICT is an inhibiting factor for economic development.

This discourse surrounding the need to bridge the global digital divide for development resonates with the bias of development as economic growth in earlier modernisation literature and the need for developing countries to 'catch up' with the economic growth indices of the developed world [Sen, 1999]. This catching up goes beyond disclosing indigenous economic development disparities between regions of the world. Symbolically, the global divide is another stigma for developing countries because it prevents them from being part of the modern world.

Relatively less attention has been given to non-economic indicators of the digital divide, although they can potentially reveal important facets of the link between ICT and development. We have little knowledge of the relationship between human development indicators and ICT indicators although such information is essential for making investment decisions 
about ICTs in the context of other possibilities. The 2001 UNDP report [2001] attempts to take a broader perspective of the significance of ICT by associating it with Sen's notion of development in terms of human capabilities [Sen, 1999], but its analysis fails to avoid the unfounded technocratic assumptions on ICT as means for improvements in critical social domains such as education or health. Norris' [2001] analysis is more thought provoking, showing that many countries that are relatively affluent display lower than average internet penetration rates like certain oil-rich countries in the Middle East as well as SE Asian countries. Cultural restrictions on the use of the Internet become important in this analysis. In another category, some societies with higher than average Internet access show low levels of economic development but significant use of human capital and R \& D potential such as Slovakia, Slovenia, Poland and Estonia. Some new democracies such as Slovenia and South Africa have achieved more advanced access to digital technologies than earlier media, suggesting that digital diffusion acquires greater significance in conditions of democratic development.

An important issue that tends to be hidden in the tables listing international digital divide indicators is the existence of in-country disparities with regard to the availability and significance of ICT and in particular internet connectivity. Kirkman et al's report on the Readiness for the Networked World recognizes that some countries, with India the most obvious example, have both highly networked ready communities and communities that are completely cut-off from the networked world that the report attempts to assess: '...India is renowned for its pre-eminence in software programming and for providing the world with highly skilled IT workers. India is effectively penalized in our Index for its size, the scope and scale of its many social and economic development challenges, and the smaller degree of IT penetration throughout the country as a whole' [Kirkman et al., 2002b, p.13]. From a development perspective, of course, the problem with an index that is insensitive to in-country variation is not that India is penalized by its ranking, but that the index brushes aside the most important development characteristic of the country, namely that the vast majority of the country's population live in poverty. The Network Readiness Indicator framework on which Kirkman et al's report is based does not provide a way of distinguishing what network connectedness means for the rural poor, the urban entrepreneur, the district authority bureaucrat, or the central government.

In all countries, there are social groups whose members both aspire to a way of living that has been developed in the modern societies of industrialised countries and have the capabilities to learn, innovate and follow relevant changes of life conditions. But for vast numbers in very many developing countries, the information, knowledge and technologies 
favoured by the initiatives of the information society have little relevance for the way they live their lives. For such populations, the push of the information society vision may be merely distractive, without the possibility to create local value out of the distraction. Most of the ICT for development is based on an a priori assumption that bridging the digital divide is a top development priority without much debate as to whether ICTs are necessary or sufficient for solving developmental problems. A small group of dissidents are cautious about the developmental promise of ICTs and argue that clean water and food should come before ICTs [Panos, 1999]. This small voice, which bears the marks of earlier Basic Needs approach to development [Green, 2002], is sidelined in the dominant discourse of ICTs for development which automatically displays intolerance to alternative investment despite little evidence of benefits and little cost-benefit analysis.

\section{ALTERNATIVE APPROACHES TO THE DIGITAL DIVIDE PROBLEM}

Our critique of the current discourse on the digital divide should not be taken to imply that ICTs do not have a position in the traditional communities of developing countries that have not developed the rationalities and the organisational and economic conditions of western industrialised societies. But it implies that alternative approaches for the mobilisation of ICTs for local needs may be more appropriate and that the resulting socio-technical conditions will not necessarily be emulating those of the advanced industrialised world and the homogeneous global information society vision. An alternative approach questions the transfer of uniform information society socio-economic practice in all communities of the world and is sensitive to the historically developed variation of socioeconomic and cultural conditions. In this chapter we can only hint at such alternative approaches emerging in the current debate on globalisation, knowledge, and social development.

The dominant view of development as following the footsteps of the advanced industrialised countries, as global socio-economic homogenisation, that is adopted in most of the information society and digital divide discourse, has been widely criticised as a mis-representation of the social transformation taking place in the contemporary world, see for example [Avgerou, 2002; Beck, 2000; Robertson, 1995]. The transformation processes are much more complex than the diffusion of uniform competent practices, the spreading of universal truths, and the acquisition of technologies pertaining to the same capabilities across social context. For example, Appadurai [1990, 1996] presents a complex picture of the link between local communities and the broader global context in terms 
of cultural flows across five dimensions of people, technology, capital, media and ideologies. To describe this process he uses the notion of 'hybridisation' as the meeting of global and local practices and ideologies. Homogenizing processes, such as trans-national business, worldwide spread of consumer products - and, we could add, ICTs and their inscriptions of best practice in a variety of tasks - are entangled with two other processes: indigenisation, and export of particular local cultural features (often indigenised global cultural features) through immigration, travel or neighbouring hegemonies. According to Appadurai, 'At least as rapidly as forces from various metropolises are brought into new media, they tend to become indigenised in one way or another' [1996, p. 32]. Recent work by development anthropologists describes the negotiations and complex processes which take place [Nelson, 1996; Schech, 2002]. Nelson provided an ethnographic account of how indigenous communities in Guatemala negotiated their position within the global information society by coming up with alternative ways of interacting with technology.

The important role of human intermediaries in any discussion of the hybridisation process between the growing digital infrastructure prevalent in developing countries and its citizens has been acknowledged [Madon, 2000; Heeks, 2002]. In developing countries, the majority of citizens are neither owners nor direct users of ICTs. Hence, ICT applications whether initiated by international or by local players rely on human intermediaries such as public servants, NGOs, community-based organisations or private sector organisations to act as a missing link between the citizen and the growing digital infrastructure such as the various e-governance projects. These local intermediaries are critical players in the delivery of relevant local content as projects are diffused from cities and towns to villages. In recent years, there has been a proliferation of such intermediaries that have sprung up in many parts of the developing world to prevent the exclusion of large sections of the population [Madon \& Sahay, 2002; Lewis \& Madon, 2003].

A promising route for understanding the capabilities disparity for benefiting from the various initiatives comprising the information society in developing countries, is offered by the concept of social exclusion that has gained popularity in European policy and academic circles in the field of social policy. The idea of social exclusion originated with the French government's concern in the mid-1970s to introduce programmes of 'insertion' for the long-term unemployed and the growing recognition that government cannot address unemployment without addressing income inequality, education, gender issues, ethnicity and other aspects of French society. Since then, many European countries have established a social exclusion unit spanning across several government departments and agencies to deal with a combination of linked social problems. The debate on social exclusion has mostly taken place in developed countries, but 
closely mirrors the debate on poverty in developing countries [O'Brien et al., 1997; Clert, 1999]. The 'value added' in the concept of social exclusion is to put institutional processes at the heart of the poverty debate through an analysis of institutions and social relations at the levels of households, communities, market and state [O'Brien et al., 1998].

While much has been written about social exclusion as a structural phenomenon produced by processes of globalisation, there is little understanding of how the dynamics of marginalisation unfold at the micro level. Beck, Madon \& Sahay [2004] seek to understand these processes through which conditions are created, sustained and refined over time. Rather than being fully included or excluded, the authors describe how marginalized groups may occupy an in-between position with the potential of movement in either direction. The direction of movement is seen as dependent on the actions of multiple parties: those that are marginalized, those who willingly or unwillingly erect or strengthen the boundaries surrounding the dominant culture, and those who seek to open those boundaries and facilitate transitions such as mediating institutions. In this way, the authors explore the degree to which human agency and sociopolitical processes shape how the information society is developed and applied to bridge the digital divide.

\section{CONCLUSION}

In short, our analysis suggests that the current push of information society reforms entails a number of risks. It makes little effort to cater for local socio-economic need, as the information society vision is geared primarily towards inclusion within the global economy, carries notions of spatially unrooted societies, and is led by imported visions of modernity. This may exacerbate existing inequalities in local social structures - as has been highlighted in industrialised countries. Moreover, the privileging of decontextualised formal knowledge, which is often drastically different from historically constructed local formal and tacit knowledge, introduces new forms of dependency. Local communities in developing countries can make no sense of such knowledge and find themselves dependent on the services of various intermediaries in order to maintain the fundamental facilities of their local communities.

At present, most international institutions involved in the initiatives of ICT diffusion in developing countries are ill-equipped conceptually to assist the development of locally meaningful ICT mediated information societies. The dominant discourse that deceptively links ICT deployment with economic growth in a global free market is incapable of addressing local efforts for the appropriation of ICTs in the diverse power/knowledge 
conditions of local communities and their interactions with numerous intermediaries. Thus, the impact of the information society vision that drives policy initiatives in most developing countries is limited to the minorities who find its global symbolic and material value meaningful within their way of living and therefore are willing and able to acquire the skills and attitudes required to exploit its potential. In the near future, the different speed at which the processes of appropriation of ICT unfolds in different social groups is likely to prolong and intensify existing social conflicts such as between urban and rural populations, westernised educated elites and traditional communities. To overcome such risks in this chapter we suggested the need for analytical approaches and policy initiatives fostering locally meaningful forms of the information society. But such approaches amount to a fundamentally different vision of the global information society, a vision which acknowledges and celebrates the emergence of hybrid forms of socio-economic activity and makes a society of diversity rather than uniformity.

\section{REFERENCES}

Appadurai, A. (1990) "Disjuncture and Difference in the Global Cultural Economy", Theory, Culture and Society, 7 pp. 295-310.

Appadurai, A. (1996) Modernity at Large: Cultural Dimensions of Globalization, University of Minnesota Press, Minneapolis.

Avgerou, C. (2002) Information Systems and Global Diversity, Oxford University Press, Oxford.

Avgerou, C. (2003) "The Link between ICT and Economic Growth in the Discourse of Development". in Information Systems Perspectives and Challenges in the Context of Globalization, Athens, Klower.

Beck, U. (2000) What Is Globalization, Polity Press, Cambridge.

Beck, E., Madon, S. and Sahay, S. (2004) "On the Margins of the Information Society: A comparative study of mediation", The Information Society, $20 \mathrm{pp}$. 279-290.

Best, M. L. and C. M. Maclay (2002) "Community Internet Access in Rural Areas: Solving the Economic Sustainability Puzzle" in The Global Information Technology Report: Readiness for the Networked World, (Kirkman, G. S., P. K. Cornelius, J. D. Sachs and K. Schwab eds) Oxford University Press, Oxford, pp. 76-89.

Castells, M. (2001) The Internet Galaxy, Oxford University Press, Oxford.

Clert, C. (1999) Evaluating the concept of social exclusion in development discourse, The European Journal of Development Research, 11, 2, pp. 176-199.

Green, M. (2002) Social Development: Issues and Approaches. In Development Theory and Practice: Critical perspectives, edited by Uma Kothari and Martin Minogue, Palgrave, Basingstoke, UK. 
Hargittai, E. (1999) Weaving the Western web: Explaining differences in Internet connectivity among OECD countries, Telecommunications Policy, Vol. 23 (1011), pp. 701-18.

Heeks, R. (2001) Understanding E-governance for Development, IDPM Working Paper Series, No. 11, University of Manchester.

Available electronically at http://www.man.ac.uk/idpm/idpm_dp.htm\#ig

Kirkman, G. S., P. K. Cornelius, J. D. Sachs and K. Schwab (2002a) "The Global Information Technology Report 2001-2002: Readiness for the Networked World" Oxford University Press New York.

Kirkman, G. S., C. Osorio, A. and J. D. Sachs (2002b) "The Networked Readiness Index: Measuring the Preparedness of Nations for the Networked World" in The Global Information Technology Report: Readiness for the Networked World, (Kirkman, G. S., P. K. Cornelius, J. D. Sachs and K. Schwab eds) Oxford University Press, New York.

Krishna, S. and S. Madon (2002) "Information \& Communication Technologies and Development: New Opportunities, Perspectives \& Challenges". in Seventh International Working Conference of IFIP WG 9.4, Bangalore, May 29-31, Indian Institute of Management Bangalore.

Lee, H., R. M. O'Keefe and K. Yun (2003) "The Growth of Broadband and Electronic Commerce in South Korea: Contributing Factors", The Information Society, 19 (1), pp. 81-95.

Lewis, D. \& Madon, S. (2003) Information systems and Non-Governmental Development Organisations: Connecting global, national and local priorities. Working Paper, Department of Information Systems.

Madon, S. (2000) "The Internet and Socio-economic Development: Exploring the Interaction", Information Technology \& People, 13, 2.

Madon, S. and Sahay, S. (2002), An information-based model of NGO-mediation for the empowerment of slum dwellers in Bangalore, The Information Society, $18,1$.

Mansell, R. and Wehn, U. (1998) Knowledge societies: Information technology for sustainable development, Oxford University Press.

Nelson, D. (1996) Maya hackers and the cyberspatialised nation state: Modernity, ethnostalgia, and a lizard queen in Guatemala, Cultural Anthropology, 11, 3, pp. 287-308.

Norris, P. (2001) Digital Divide: Civic Engagement, Information Poverty, and the Internet Worldwide, Cambridge University Press, Cambridge.

O'Brien, D., Wilkes, J., de Haan, A., Maxwell, S. (1998) Poverty and Social Exclusion in North and South. Institute of Development Studies and Poverty Research Unit, IDS Working Paper 55, University of Sussex.

PANOS (1998) The Internet and Poverty: Real help or real hype? The Panos Institute Information Technology Media Briefing No. 28, London. (http://www. Panos.org.uk)

Porter, M. E., et al. (2002) "The Global Competitiveness Report 2001-2002" Oxford University Press New York. 
Robertson, R. (1995) "Glocalization: Time-Space and Homogeneity-Heterogeneity" in Global Modernities, (Featherstone, M., S. Lash and R. Robertson eds) Sage, London, pp. 25-44.

Rodriguez, F. and Wilson, E. (2000) Are poor countries losing the information revolution? World Bank InfoDev Report.

Sen, A. (1999) Development as Freedom, Oxford University Press, Oxford.

Schech, S. (2002) "Wired for Change: The links between ICTs and Development Discourses", Journal of International Development, 14, pp. 13-23.

United Nations Development Programme (2001) "Making New Technologies Work for Human Development" UNDP New York.

World Bank. (1999) World Development Report 1998/99. Knowledge for Development, Oxford University Press, Oxford.

World Bank (2002) "Building Institutions for Markets" New York.

Wolfensohn, J.D. (2000) Speech made by the President of the World Bank, February 2000.

Wresch, W. (1996) Information Rich, Information Poor. In Disconnected: Haves and Have-nots in the Information Age, Rutgers University Press, New Jersey. 